\section{Differentiation and decrement in the Mueller-Lyer illusion*}

\author{
STANLEY COREN \\ The New School for Social Research, New York, New York 10011 \\ and \\ JOAN S. GIRGUS \\ The City College of the City University of New York \\ New York, New York 10031
}

Two experiments were conducted to test the hypothesis that decrement of
the Mueller-Lyer illusion with inspection is due to learning to differentiate the
test element from the accessory lines. In one experiment, the test element is
predifferentiated for the observer by means of configurational variations and in
the other by restriction of attention. Although the initial magnitude of the
illusion is found to be inversely proportional to the amount of
predifferentiation, the slopes of the decrement curves are not affected.

Around the turn of the century, when the visual-geometric illusions were first studied quantitatively, a number of investigators noticed that the measured magnitude of an illusion seemed to diminish with continued inspection. Several investigators reported such a decrement in the magnitude of the Mueller-Lyer illusion (Heymans, 1896; Judd, 1902, 1905; Lewis, 1908). Their observations have since been confirmed by many others (Crossland, Taylor, \& Newsom, 1929; Day, 1962; Dewar, 1968; Mountjoy, 1961; Parker \& Newbigging, 1965). In addition to the extensive work on the Mueller-Lyer configuration, there has been research indicating that a number of other illusions, including the Poggendorf, the Zoellner, and the Wundt-Hering illusions, also show a reduction in strength after prolonged viewing (Cameron \& Steele, 1905; Coren \& Girgus, 1972).

Although the existence of illusion decrement has long been recognized, very few theoretical explanations of this phenomenon exist. The three most current explanations are based upon either cortical satiation processes, eye movements, or differentiation.

The cortical satiation hypothesis was introduced by Kohler and Wallach (1944). Its application to illusion decrement was tested by Kohler and Fishback (1950) on the Mueller-Lyer figure. This theory argues that regions of the cortex involved in the representation of contours become satiated from prolonged stimulation and thus cannot process any further stimulation. This results in a shift of the apparent locus of the contour away from the region of maximum satiation. For the Mueller-Lyer figure,

\footnotetext{
* We gratefully acknowledge the assistance of Francine Shapiro, Leah collection and the analysis of these data.
}

the maximum satiation develops in the vertex of the angles between the wings and the horizontals. The resultant contour shifts are in the direction toward which the vertices point, resulting in a diminished illusion. Unfortunately, this theory has not withstood experimental tests very well. Steady fixation should optimize result in maximal decrement. larger decrement for free eye movement conditions than for fixation conditions (Day, 1962; Festinger, White, \& Allyn, 1968; Hoenig, 1972). In addition, rotating the figure $180 \mathrm{deg}$ on each trial, a procedure which ought to cancel systematic contour shifts, does not eliminate the occurrence of decrement (Moed, 1959).

Eye movement involvement in visual illusions was first suggested by Wundt (1898). Numerous investigators have shown that eye movements are longer for the apparently longer segment of the Mueller-Lyer than for the apparently shorter segment (Delabarre, 1897; DeSisto \& Moses, 1968; Festinger, White, \& Allyn, 1968; Judd, 1905; Stratton, 1906; Yarbus, 1967). When eye movements are used to explain illusion decrement, the argument is generally made that information about the nature of the distortion is obtained from the erroneously longer or shorter saccades. Information thus obtained about the direction and extent of the distortion can be used to reprogram both the eye movements and the percept to a more veridical form. This position has received some support from studies which show that decrement is greater when saccadic eye movements are allowed (Burnham, 1968; Festinger, White, A Allyn, 1968; Hoenig, 1972). It is difficult, however, to reconcile this theory with the numerous studies which have reported diminution of the the effects of satiation and should However, some investigators report illusion under conditions of steady fixation (Day, 1962; Kohler \& Fishback, 1950; Moed, 1959; Selkin \& Wertheimer, 1957).

Since the initial speculations of Mueller-Lyer himself (1889), theorists have been offering illusion theories based upon "confusion" of the test and inducing elements or upon the "total impression" of the figure (Carr, 1935; Erlebacher \& Sekuler, 1969). The corollary illusion decrement theory simply states that illusion reduction is due to a process of gradually learning to ignore the accessory lines in the configuration and to base the perceptual judgment upon the test element alone. This theory of illusion decrement has a long history which includes Benussi (1904, 1912), Carr (1935), Ladd \& Woodworth (1911), and Lewis (1908). The process involved seems somewhat similar to the differentiation mechanism offered by Gibson (1969) to explain how observers learn to isolate various pictorial dimensions simply through inspection of a pattern. Although there is some evidence that perceptually isolating the test elements in some illusions through the use of spatial separation or different colors does indeed reduce the measured magnitude of the illusion (Bennussi, 1904; Segall, Campbell, \& Herskovitz, 1966), no direct test of the differentiation hypothesis as applied to illusion decrement has yet been attempted. Such a test may be effected by considering several implications of this hypothesis. If the illusion is the result of "confusion" between test and inducing elements, then an illusion figure in which the test elements have already been partially isolated by configurational or instructional manipulations should manifest less of a distortion. In addition, if decrement of the illusion with practice is simply the result of perceptual segregation of the test element from the adjacent illusion-producing elements, then this prior isolation should lead to less decrement with practice. The lessened decrement should result from the fact that much of the differentiation usually responsible for the decrement has already been accomplished by the configurational manipulations. This implies that with figures of varying degrees of predifferentiation, there should be comparably different amounts of initial illusion, followed by a convergence of the decrement curves to an asymptote representing maximum differentiation. The following experiments were conducted to test these predictions.

\section{EXPERIMENT 1}

In this experiment, an attempt was 

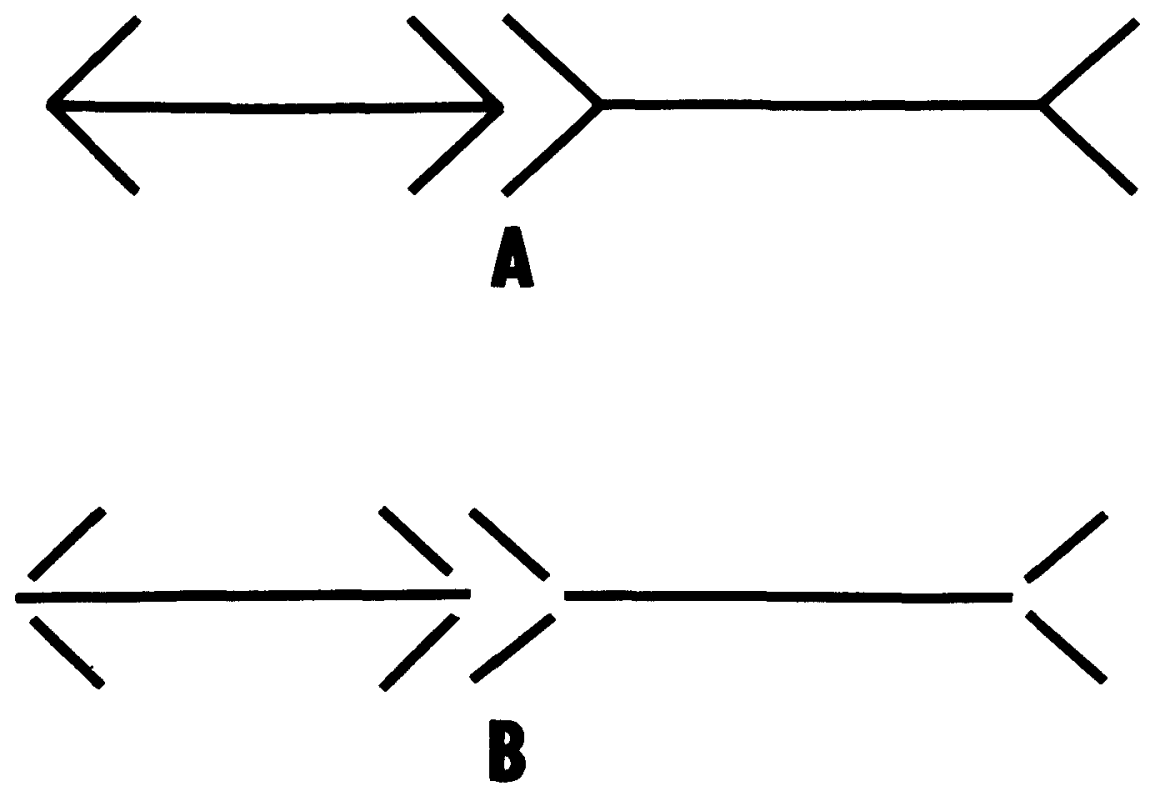

Fig. 1. The configurational variants of the Mueller-Lyer figure used in Experiment 1. The continuous form is shown in $A$ and the separated form in $B$. made to vary the initial degree of differentiation in a Mueller-Lyer figure by the use of spatial separation and/or color differences between test and inducing elements. volunteers were randomly assigned to

Stimuli. Four variants of the Mueller-Lyer illusion were constructed, each with a different kind and/or amount of articulation between the wings and shaft. The horizontal segment of the figures were $8 \mathrm{~cm}$ in length, with 2-cm wings at an angle of $45 \mathrm{deg}$ from the horizontal. All lines in the figure were $1 \mathrm{~mm}$ wide. The wings were either continuous with the shaft or separated by a gap of $2 \mathrm{~mm}$. The continuous form of the illusion used in this experiment is shown in Fig. 1A, and the spatially separated form is shown in Fig. 1B. In addition to the presence or absence of spatial separation, the wings and the shaft could be presented in the same color or in different colors. The shaft was always blue (Munsell equivalent 5B 7/6, reflectance $31.7 \%$ ), while the wings could be either the same blue or an orange (Munsell equivalent $5 Y R 7 / 10$, reflectance $31.8 \%$ ). The apparently longer segment of each illusion configuration was adjustable through the use of a tongue-in-groove arrangement, and readings were made from a millimeter scale affixed to the adjustable slide.

Procedure. The operation of the apparatus was first explained to each S. He was then required to set the

\section{Subjects. Method} one of four conditions. terms of the difference between the length set as apparently equal and the physical length of the shaft. This initial measure was followed by a 5-min inspection period with free eye movements. During the inspection period, measures of illusion magnitude were taken at $1-\mathrm{min}$ intervals.

\section{Results}

The results of Experiment 1 are shown in Fig. 2. Looking at the initial illusion magnitude, it is clear that increasing the articulation of the figure by perceptual separation of the test lines from the inducing lines results in a reduced illusion $(F=7.29, \mathrm{df}=3 / 36$, $p<.01)$. This result is clearly in accord with a confusion theory of visual illusions, since the less confusable the test and inducing elements, the lower the initial magnitude of the illusion. The initial magnitude of the illusion is decreased by close to $36 \%$ if only spatial separation or color differentiation is used and by nearly $60 \%$ when both are combined.

Let us now turn to the relative amount of decrement as a function of these various degrees of differentiation. It is clear that all of were apparently equal in length. This gives a measure of illusion strength in
I COLOR CONTINUOUS

I COLOR SEPARATED

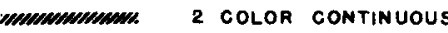

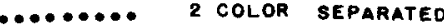
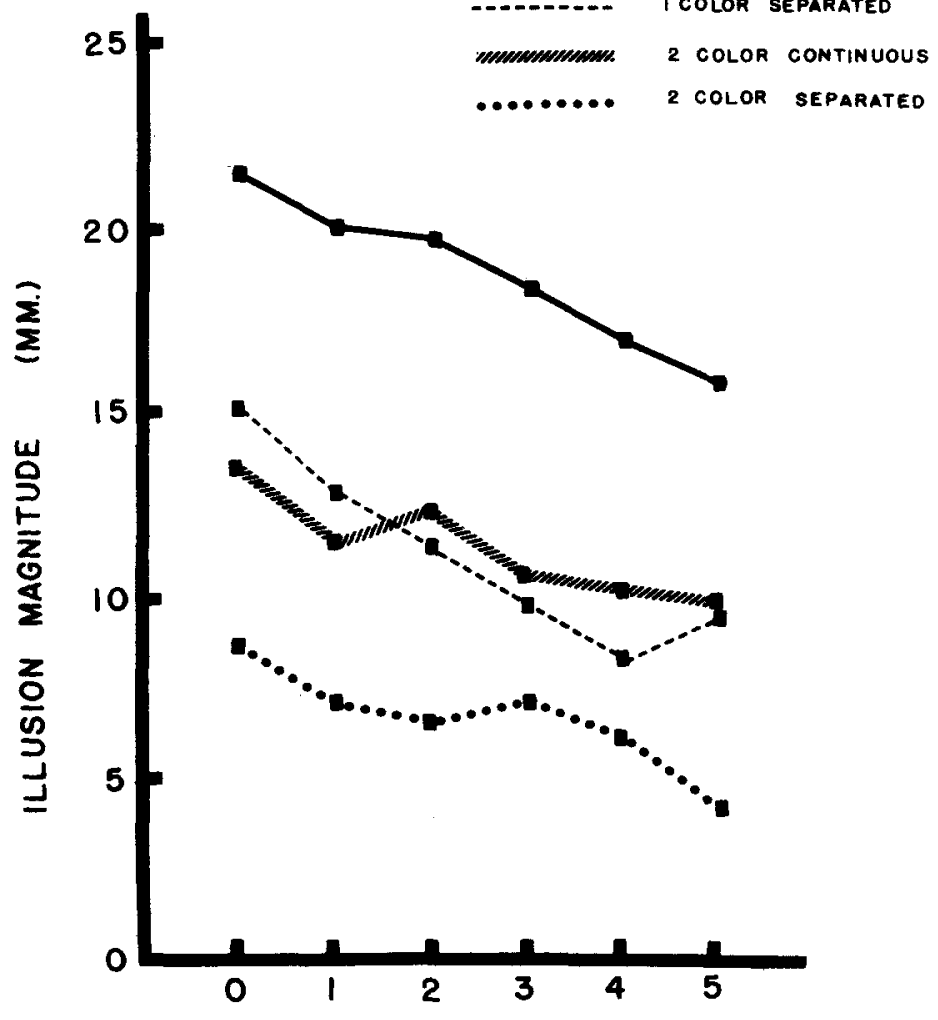

TIME (MINUTES)

Fig. 2. Mlusion magnitude is plotted as a function of viewing time for the four illusion variants tested in Experiment 1. 
the configurations manifest a decrement in magnitude over the inspection period $(F=13.63, \mathrm{df}=$ $5 / 180, p<.01)$. None of the illusion configurations decrement to zero, and there were no systematic changes in variability as a function of the amount of decrement. The important question, however, is the relative amount of decrement among the configurations. It was hypothesized that the predifferentiated illusion figures would show less decrement than the illusion figure in which no prior differentiation had been effected for $S$. This should manifest itself as a significant interaction. Such an interaction is not obtained, however $(F=0.63$, df $=15 / 180)$, and the curves showing the reduction of the illusion with inspection all appear relatively parallel. It seems that whatever is occurring in the decrement of these figures is apparently independent of the initial degree of articulation of the figure.

It may be argued, however, that the initial diminution of illusion magnitude as a function of illusion configuration observed above is due, not to differentiation, but rather to a reduction of peripheral effects which may contribute to the magnitude of the illusion. Such effects may include lateral inhibition (Békésy, 1967; Ganz, 1966) and optical aberration (Chiang, 1968), both of each operate maximally at the intersection of converging lines. It has been demonstrated that changing illusion configurations so that lateral inhibition or optical aberrations cannot work as effectively results in a reduction in illusion magnitude (Coren, 1969, 1970). The spatially separated forms used in this experiment would certainly provide reduced opportunity for either lateral interactions or optical effects to manifest themselves. In addition, current evidence seems to indicate that lateral inhibitory interactions are seldom present between different color coding systems. Many investigators report that lateral inhibitory phenomena, such as Mach bands, do not appear when brightness is equated but the stimuli differ in color (Ercoles-Guzzoni \& Fiorentini, 1958; Fry, 1948). When such interactions are found, they are generally weak or applicable only to restricted stimulus arrays (Daw, 1964; Jacobson, 1967; Jacobson \& MacKinnon, 1969). It may therefore be the case that the illusion configurations used in this study merely affected the peripheral components of the illusion and not the cognitive differentiation processes that we had hoped to manipulate. If this is the case, Ss must still learn to restrict their attention to the test element and to ignore the wings during the inspection period. Each group may do this at the same rate, thus producing the parallel curves for illusion decrement obtained in Experiment 1. One way to deal with these possible difficulties is to manipulate the initial degree of differentiation by manipulating the distribution of attention rather than the configuration. Thus, if Ss are given an instruction to restrict their attention to the test shaft and to ignore the inducing elements, as done by Benussi (1904), we would predict a reduced initial illusion. Such a restriction of attention would reflect an increased attempt to differentiate the test element from the accessory lines initially. To the extent that it is successful, there is less differentiation left to be accomplished during the inspection period. Thus, we would expect a reduced rate of decrement for a group that has already differentiated the shaft from the wings through the operation of this particular viewing set. In order to test this prediction, Experiment 2 was conducted.

\section{EXPERIMENT 2}

In this experiment, the degree of articulation of the figure is effected by an instructional manipulation rather than by a configurational manipulation.

Subjects. Twenty undergraduate volunteers were assigned randomly to one of two instructional conditions.

Stimulus and procedure. The one-color continuous stimulus used in Experiment 1 was used in this experiment. Ss received one of two sets of instructions at the beginning of the session. The differentiation instruction asked $S$ to attend to the horizontal line only and to ignore the wings throughout the experiment, while the normal instructions did not include this restrictive attentional set. As in Experiment 1, a premeasure of illusion magnitude was taken, followed by $5 \mathrm{~min}$ of inspection of the figure with free eye movements for both groups. During the inspection period, measurements of apparent equality were taken at $1-\mathrm{min}$ intervals.

\section{Results}

The results are shown in Fig. 3. It is clear that the restriction of attention to the shaft does reduce the initial magnitude of the illusion $(t=2.47, \mathrm{df}$ $=18, \mathrm{p}<.05)$. This result provides further support for confusion theory if one assumes that such a restriction of attention reduces the ability of the wings to contribute to the total impression of the figure. To the extent that this reduction in illusion magnitude reflects differentiation of the shaft from the wings through the operation of the altered viewing set, we may now turn to the relative magnitude of the decrements to test our hypothesis. It is clear that both groups decrement significantly $(F=$ 31.61, df $=5 / 60, p<.01$ ). Again, the prediction from the differentiation hypothesis is that, since much cognitive differentiation has occurred as a result of the altered instructions, there should be less differentiation left to accomplish during inspection. We, thus, would expect less absolute decrement in the restricted attention group than in the normal instruction group. Again, this difference should manifest itself statistically as an interaction; however, none is found ( $F$ $=0.769$, df $=5 / 60)$. Despite the predifferentiation through instructional set, both groups show approximately the same amount of decrement.

\section{DISCUSSION}

The present data seem clearly to indicate that differentiation of the test shaft from the inducing lines reduces the initial magnitude of the illusion. Both spatial separation and color separation of the parts of the figure reduce initial illusion magnitude and a combination of both of these forms of articulation diminishes the illusion even further. Similarly, changing the viewing set by restricting S's attention so that the inducing elements are no longer as heavily weighted seems to reduce the illusory effect. All of these findings may be taken as support for the general class of theories that propose cognitive components in illusion formation. The theoretical position most strongly supported by these data is "confusion theory" such as that recently revived by Erlebacher and Sekuler (1969).

These two experiments, taken together, however, also seem to indicate that illusion decrement with inspection is not simply due to a gradual differentiation of the test element from the accessory lines. Differentiation theories would predict that the predifferentiated forms of the illusion would show a reduced rate of decrement. Yet, despite the increased predifferentiation provided by changes in the configuration or the viewing set, the diminution of illusion magnitude with prolonged exposure remains the same. It is conceivable that the predifferentiation of the figures might not be expected to alter the slope of the decrement curves but rather the time which is needed to reach asymptote. Under the alternative, the curves would be expected to flatten as they near the asymptotic level; this 


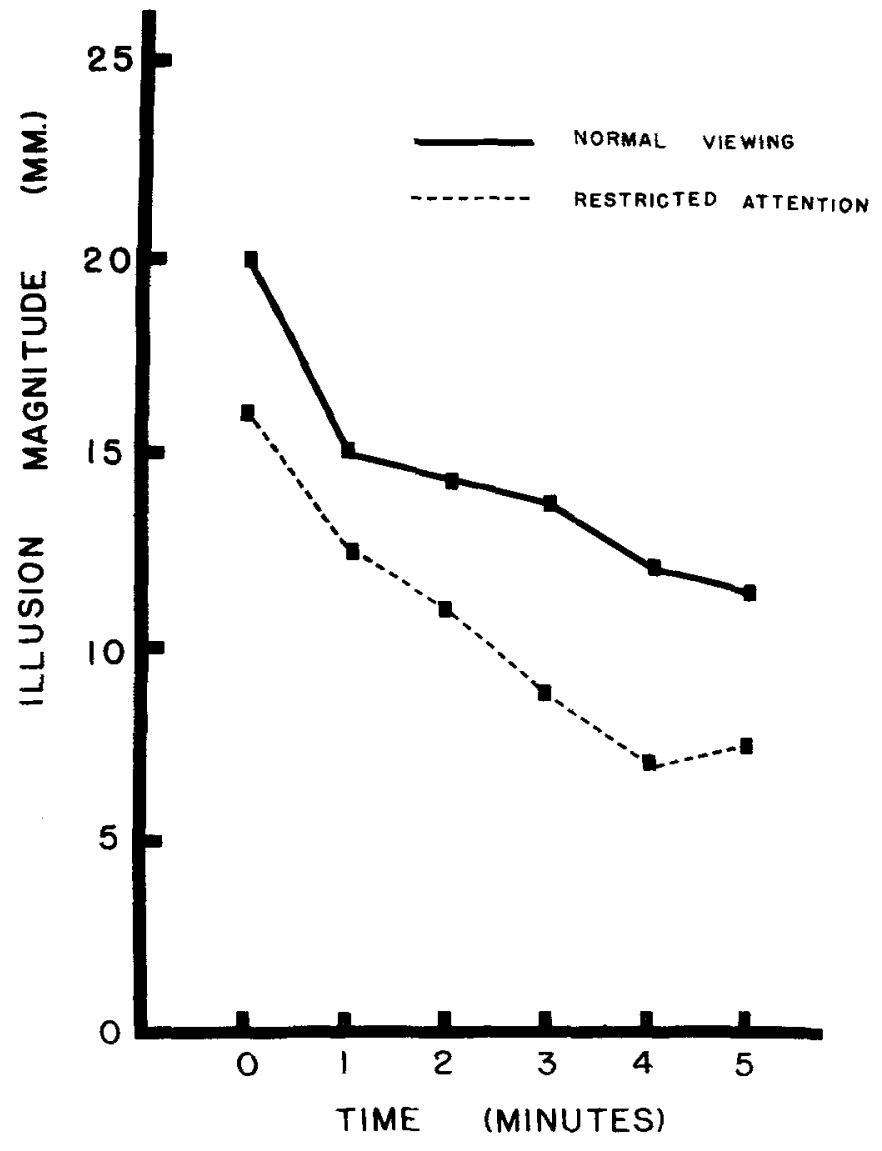

Fig. 3. Illusion magnitude is plotted as a function of viewing time for the two attentional conditions tested in Experiment 2 .

should still manifest itself in the shape of the curves and in a statistical interaction in the data presented above. Of course, the only way to test this proposition thoroughly is to decrement the illusions until there is no further visible change in level. This is extremely time consuming, since it took Judd (1902) better than 25 days to reduce the Mueller-Lyer to an asymptotic level and Dewar (1967) finds no evidence for a flattening out of the decrement curves, even after 100 trials.

We can still only speculate about the actual basis for decrement in illusion magnitude with inspection. Our Ss were allowed free eye movements over the figures, and thus the opportunity for correction of erroneously programmed eye movements existed in these studies. It has been suggested that such eye movement correction might underlie illusion decrements (Festinger, White, \& Allyn, 1968). This explanation does not seem to be in conflict with the present data, although we can clearly neither confirm nor deny it with these data. The clearest conclusions to emerge from these experiments is that, although differentiation of the test element from the accessory illusion-producing lines seems to contribute to initial illusion magnitude, it does not seem to be an adequate explanation of the diminution of illusion magnitude with inspection.

\section{REFERENCES}

ESY, G. von. Sensory inhibition. Princeton N.J: Princeton University Press, 1967.

BENUSSI, v. Zur Psychologie des Gestalterfassens (die Muller-L yersche Figur) In A. Meinong (Ed.) Untersuchungen zur Gegenstandstheorie und Psychologie. Leipzig: Barth, 1904.

BENUSSI, V. Stroboskopische s chien bewegungen und Geometrischoptishe Gestalttauschungen. Archiv fur die Gesamte Psychologie, $1912,24,169-181$.

BURNHAM, C. A. Decrement in the Müller-Lyer illusion with saccadic and tracking eye movements. Perception \& Psychophysics, 1968, 3, 424-426.

CAMERON, E. H., \& STEELE, W. M. The Poggendorf illusion. Psychological Review, 1905, 7(Monogr. Suppl. 29), 83-111.

CARR, H. A. An introduction to space perception. New York: Longmans, Green, 1935.

CHIANG, C. A. A new theory to explain geometrical illusions produced by crossing lines. Perception \& Psychophysics, 1968, 3, 174-176.
COREN, S. The influence of optical aberrations on the magnitude of the Poggendorff illusion. Perception \& Psychophysics, 1969,6, 185-186.

COREN S Lateral inhibition and geometric illusions. Quarterly Journal of Experimental Psychology, 1970, 22 , 274-278.

COREN, S., \& GIRGUS, J. S. Illusion decrement in intersecting line figures. Psychonomic Science, 1972, 26, 108-110.

CROSLAND, H. R., TAYLOR, H. R., \& NEWSOM, S. J. Practice and improvability in the Mueller-Lyer illusion in relation to intelligence. Journal of General Psy chology, 1929, 2, 290-305.

DAW, N. W. Visual response to gradients of varying colour and equal luminance. Nature, 1964, 203, 215-216.

DAY, R. H. The effects of repeated trials and prolonged fixation on error in the Mueller-Lyer figure. Psycholozical Monographs, 1962, 76(14, Whole No. 533 ).

DELABARRE, E. B. A method of recording eye-movements. American Journal of Psychology, 1897, 9, 572-574.

DeSISTO, M. J., \& MÓSES, F. L. Saccadic eye-movement response to Mueller-Lyer stimuli. Paper read at a meeting of the Eastern Psychological Association. Washington, D.C., April 19, 1968.

DEWAR, R. E. Stimulus determinants of the practice decrement of the Mueller-Lyer illusion. Canadian Journal of Psychology, 1967, 21, 504-520.

DEWAR R E Distribution of practice and the Mueller-Lyer illusion. Perception \& Psychophysics, 1968, 3, 246-248

ERCOLES-GUZZÓNI, A. M., \& FIORENTINI, A. Simultaneous contrast effect produced by non-uniform coloured fields. Atti Fondazione Giorgio Ronchi, 1958, XIII, 135-144.

ERLEBACHER, A., \& SEKULER, R. Explanation of the Mueller-L yer illusion Confusion theory examined. Journal of Experimental Psychology, 1969, 80, 462-467.

FESTINGER, L., WHITE, C. W., \& ALLYN, $M$. R. Eye movements and decrement in the Mueller-Lyer illusion. Perception \& Psychophysics, 1968, 3, 376-382.

FRY G. A. Mechanisms subserving simultaneous brightness contrast American Journal of Optometry \& Archives of the American Academy of Optometry, $1948,53,94-97$.

GANZ, L. Mechanism of the figural aftereffects. Psychological Review, 1966 , $73,128-150$.

GIBSON, E. J. Principles of perceptual learning and development. New York: Appleton-Century-Crofts, 1969.

HEYMAN S, G. Quantitative Untersuchungen uber das "optischen Paradoxen." Zeitschrift für Psychologie, $1896,9,221-255$

HOENIG $p$. The effects of eye movements. fixation and figure size on decrement in the Mueller-Lyer illusion. Unpublished doctoral dissertation, New School for Social Research, 1972

JACOBSON, J Z Saturation Mach bands. MA thesis, University of Waterloo, 1967. JACOBSON, J. Z., \& MackINNON, G, E Coloured Mach bands. Canadian Jouma of Psychology, 1969, 23, 56-65.

JUDD, C. H. Practice and its effects on the perception of illusions. Psychological Review, 1902, 9, 27-39.

JUDD, $C$. H. The Mueller-Lyer illusion. Psychological Review, Monograph Supplement, 1905, 7(Whole No. 29), 55-81.

KOHLER W \& FISHBACK, J. The destruction of the Mueller-Lyer illusion in repeated trials: I. An examination of two theories. Journal of Experimental Psy chology, 1950, 40, 267-281.

KOHLER W. \& WALLACH, H. Fieural after-effects. An investigation of visual processes. Proceedings of the American 
Philosophical Society, 1944, 88, 269-357. LADD, G. T. \& WOODWORTH, R. S Elements of physiological psychology. New York: Scribner's, 1911.

LEWIS, $E$. O. The effect of practice on the perception of the Mueller-Lyer illusion. British Journal of Psychology, 1908, 2. 294-306.

MOED. G. Satiation-theory and the Muller-Lyer illusion. American Journal of Psychology, 1959, 72, 609-611.

MOUNTJOY, P. T. Intrasession decrement and intersession recovery to the Mueller-Lyer figure. Perceptual \& Motor Skills, 1961, 13, 51-57.

M t'LLER-LYER, F. C. Optische
U rteilstaeuschungen. Dubois-Reymonds Archiv fuer Anatomie und Physiologie, 1889, Suppl. Vol., 263-270.

PARKER, N. I., \& NEWBIGGING, P. L. Decrement of the Muller-L yer illusion as a function of psychophysical procedures. American Journal of Psychology, 1965. 78, 603-608.

SEGALI, M. H., CAMPBELL, D. T., \& HERSKOVITZ, M. J. The influence of culture on visual perception. Indianapolis, Ind: Bobbs-Merrill, 1966.

SELKIN, J., \& WERTHEIMER, M. Disappearance of the Mueller-L yer illusion under prolonged inspection. Perceptual \& Motor Skills, 1957, 7,
265-266.

STRATTON, G. M. Symmetry, linear illusions, and the movements of the eye. Psychological Review, 1906, 13,82-96. WUNDT, W. Die geometrisch-optischen Taeuschungen. Abhandlungen der mathematisch physischen Classe de Koeniglischen Saechsischen Gesellschaft der Wissenschaften, 1898,42 , No. 2.

Y AR BUS, A. L. Eye movements and vision. (Trans. B. Haigh) New York: Plenum Press, 1967.

(Received for publication June 6, 1972; revision received July 23,1972 .) 